\title{
Training Programs, T-Series
}

National Cancer Institute

\section{Source}

National Cancer Institute. Training Programs, T-Series. NCI Thesaurus. Code C19076.

T14: Conferences--To provide the chairman of the training committee funds for operation of the review group. T32: Institutional National Research Service Award -To enable institutions to make National Research Service Awards to individuals selected by them for predoctoral and postdoctoral research training in specified shortage areas. Also see National Research Service Award (NRSA) Stipend Increase. T34: MARC Underg raduate NRSA Institutional Grants -To enable minority institutions to make National Research Service Awards to individuals selected by them for underg raduate research training in the biomedical and behavioral sciences. T35: NRSA Short-Term Research Training -To provide individuals with research training during off-quarters or summer periods to encourage research careers and/or research in areas of national need. 